\title{
Temporal coding by young and elderly adults in a list-discrimination setting
}

\author{
P. D. McCORMACK \\ Carleton University, Ottawa, Canada
}

\begin{abstract}
A list-discrimination task was administered to each of 60 young and 60 elderly females, who were presented with 20 words and then, after a 1 -min interval, 20 more. They were then required to indicate list membership for each of the $\mathbf{4 0}$ words. The young performed more accurately than the elderly, but awareness of the task requirements did not facilitate performance relative to that in an unaware treatment condition. There was no evidence for differential strategies or differential response biases with respect to age. The findings were discussed within the context of the notion that the temporal attribute of memory is processed "automatically."
\end{abstract}

According to Hasher and Zacks (1979), there are "automatic" memory-coding operations that process the fundamental attributes of memory, namely, space, time, and frequency-of-occurrence information. The effectiveness of these operations is assumed to show minimal deterioration throughout the lifespan. There are two studies in the literature involving the temporal attribute of memory that present conflicting findings regarding the age-invariance prediction. In the first of these (McCormack, 1981), young and elderly adults listened to a list of words and then gave their best estimates of the list location of each word. As predicted by the Hasher-Zacks model, no reliable age differences in location memory were observed, and awareness of the location requirement had no reliable effect on performance. The dependent variable in this study, however, was based on an adjusted index of location measure (Toglia \& Kimble, 1976), a transformation that may have serious flaws (McCormack, 1982a). In the second investigation involving the temporal attribute (McCormack, 1982b), a series of words was presented to young and elderly adults, followed immediately by pairs of items from the list, at which time recency judgments were requested. There was a substantial difference in performance that favored the young and that was more in line with the study-phase retrieval model of Tzeng and Cotton (1980) than with that of Hasher and Zacks. These findings, however, are not necessarily in conflict with the age-invariance prediction, since an "effortfull"' process likely was involved.

The purpose of the present study was to provide yet another test of the Hasher-Zacks (1979) model,

This study was funded by the Natural Sciences and Engineering Research Council of Canada, Grant A7498. The author wishes to acknowledge the assistance of Marjorie Coristine for testing the subjects. Requests for reprints should be sent to P. D. McCormack, Department of Psychology, Carleton University, Ottawa, Ontario, Canada KIS 5B6. again in the context of temporal coding. The task was modeled after that of Underwood (1977), in which subjects, after having been presented three lists of words, were asked to indicate the list membership of each item. In the present study, only two lists were employed. The Hasher-Zacks prediction that subjects aware of the requirement of judging list membership would perform no better than those who were unaware was also tested.

\section{METHOD}

\section{Subjects}

One-hundred and twenty females participated in the experiment. Sixty of these were elderly (mean age $=67.52$ years, $S D=4.81$ years). They were obtained from a subject pool described elsewhere (McCormack, 1981). The remaining 60 females had a mean age of 19.80 years $(\mathrm{SD}=2.66$ years), and all were students of introductory psychology.

\section{Materials}

Forty four-letter nouns were selected from the norms of Paivio, Yuille, and Madigan (1968). The words' mean imagery, concreteness, and meaningfulness values were as follows: $6.44(\mathrm{SD}=.24)$, $6.85(\mathrm{SD}=.13)$, and $6.83(\mathrm{SD}=.84)$. A computer program was written to create, for each subject, a unique random order of 20 words for the first list, a unique random order for the remaining 20 words for the second list, and a unique random order of all of the $\mathbf{4 0}$ words for test.

\section{Procedure}

The elderly were tested individually in their residences and the young in the laboratory. In the study phase, 20 words were read aloud by the experimenter for about $2 \mathrm{sec}$ each. Following a 1 -min interval, the 20 remaining words were read aloud. During the test phase, which followed immediately, the $\mathbf{4 0}$ words were given to the subject on a single sheet of paper, with the numbers 1 and 2 alongside each word. The subject's task was to circle the number corresponding to the list in which she felt the word belonged. The test phase was self-paced. For each age group, half the subjects were aware of the task requirements, whereas the remaining subjects were told to prepare for a later memory test. For each of the two awareness conditions, half the subjects had the 1-min interlist interval filled with conversation with the experimenter, whereas the remaining subjects were not allowed to engage in conversation. 


\section{RESULTS AND DISCUSSION}

An analysis of variance for a 2 (young vs. elderly) $\times 2$ (aware vs. unaware) $\times 2$ (filled vs. unfilled interval) $\times 2$ (List 1 vs. List 2) design, with the first three factors as between-subjects measures and the last as a repeated measure, was performed on the number of correct placements of words in their respective lists. The age main effect was significant $[F(1,112)=11.69$, $\mathrm{p}<.005$ ], the mean number of correct placements for the young and elderly, respectively, being 29.33/40 and $26.48 / 40$. Both groups clearly performed at much better than chance levels. The list main effect, reflecting recency, was also significant $[F(1,112)=6.53$, $\mathrm{p}<.025$ ], the mean number of correct placements for Lists 1 and 2, respectively, being 13.64/20 and 14.27/ 20. No other main effects, or interactions, were significant. The age main effect favoring the young was at variance with the Hasher-Zacks (1979) prediction. On the other hand, the absence of an awareness main effect was not inconsistent with the notion of an "automatic" process. Of particular interest was the absence of a significant age $\times$ awareness interaction, since one might expect the young to employ strategies that would enhance their performance under the "aware" condition. One such strategy would be simply to ignore completely the List 1 words. Also of interest was the absence of a significant interval main effect, since the unfilled condition provided the subjects with the opportunity to rehearse List 1 items. This may, in fact, have been the case, with the effect of rehearsal being less potent than that of recency.

A second analysis was performed, this time on the frequency with which the subjects chose words as belonging to Lists 1 and 2, the purpose being to reveal any differential response biases on the part of the two age groups. Such biases have been observed in other investigations (e.g., McCormack, 1981), and when they occur, they often complicate the interpretation of the findings. Since all subjects circled a number for all $\mathbf{4 0}$ words, the only main effect was that of lists, and the only meaningful interactions were those involving lists. The main effect of lists was significant $[F(1,112)=6.87, p<.025]$, the means for Lists 1 and
2 , respectively, being 19.35 and 20.65 . This bias to circle the number 2 , however, was not differential with respect to age, since the age $\times$ lists interaction was not significant.

It must be concluded, then, that the performance of the young was superior to that of the elderly, and that this likely cannot be attributed to strategy or bias differences between the two age groups. When these findings are considered along with those of the other two studies involving the temporal attribute of memory (McCormack, 1981, 1982b), it must be concluded that there is little support for that portion of the Hasher-Zacks (1979) model that predicts age invariance. Their postulate, which leads to the prediction of no differences in performance on the part of aware and unaware subjects, however, was supported here, as well as in the one other temporal study in which this manipulation was made (McCormack, 1981).

\section{REFERENCES}

Hasher, L., \& ZACks, R. T. (1979). Automatic and effortful processes in memory. Journal of Experimental Psychology: General, 108, 356-388.

McCormack, P. D. (1981). Temporal coding by young and elderly adults: A test of the Hasher-Zacks model. Developmental Psychology, 17, 509-515.

McCormaCK, P. D. (1982a). The adjusted index of location: Some methodological considerations. Bulletin of the Psychonomic Society, 19, 331-333.

McCormack, P. D. (1982b). Temporal coding and study-phase retrieval in young and elderly adults. Bulletin of the Psychonomic Society, 20, 242-244.

Paivio, A., Yuille, J. C., \& Madigan, S. A. (1968). Concreteness, imagery, and meaningfulness values for 925 nouns. Journal of Experimental Psychology Monographs, 76(1, Pt. 2).

Toglia, M. P., \& Kimble, G. A. (1976). Recall and use of serial position information. Journal of Experimental Psychology: Human Learning and Memory, 2, 431-435.

Tzeng, O. J. L., \& Cotton, B. (1980). A study-phase retrieval model of temporal coding. Journal of Experimental Psychology: Human Learning and Memory, 6, 705-716.

UNDE RWOoD, B. J. (1977). Temporal codes for memories: Issues and problems. Hillsdale, NJ: Erlbaum.

(Manuscript received for publication May 7, 1984.) 